\title{
Numerical Simulation of channel Frost Heaving Characteristics of Delivery State in Winter
}

\author{
DU Mingrui ${ }^{1}$, SONG Ling $^{1,}$ a, CHEN Ruikao ${ }^{1}$ and WEI Peng ${ }^{1}$ \\ ${ }^{1}$ College of Water \& Architectural Engineering, Shihezi University, Shihezi 832003,China \\ a741518448@qq.com
}

\begin{abstract}
Keywords: Winter delivery; Temperature; Finite element; Freezing surface
Abstract. Based on the measured data of Shihezi power plant four Hongshanzui water channels and lining channel frost heaving characteristics. According to the theory of frozen soil mechanics,use the convection heat transfer formula and the temperature field was analyzed with nonlinear method of the software ANSYS.Winter water conveyance concrete channel in process of frost heave was simulated.Study on the water channel in the winter under the condition of frost heaving deformation. Numerical results of the simulation demonstrate without considering the difference of channel water under the condition of winter frost heaving force and tangential frost heaving force and the force of water channel and failure position shift. It would obviously be impractical to design channel for water conveyance according to past experience.
\end{abstract}

\section{Introduction}

Since trapezoidal concrete-lined channel is similar to circular cross-section, it is widely used in engineering practice. But in seasonal frozen area, channel lining is damaged by frost heaving damage, which brings bigger challenge for construction of channel and even the whole water conservancy project design.There has been a lot of researches on ordinary frost heaving model for lining channel.In 1973, RL Harlan put forward, for the first time, the concept of hydro-thermal coupling and established the coupling model[1]. On this basis, Shen $\mathrm{Mu}$ and Branko Ladanyi[2] brought up temperature, moisture and stress fields coupling in 1990 and established the simplified coupling model. By experimental data and theoretical analysis, Konrad etal. [3] proposed the concept of segregation potential and defined it as the ratio between soil moisture migration rate and temperature gradient. An Weidong [4] made theoretical discussion on temperature, moisture and stress fields coupling for frozen soil and carried out numerical simulation with the example of problems in some roads and water conservancy projects.However, there is another type of conveyance channel operated in winter, such as diversion channel, seepage-proof channel used for urban water supply and conveyance channel in inter-basin water diversion project. Such kind of conveyance channel is not only faced with ice cover above water surface but also serious frost heaving damage in some of its channel sections.Considering the interaction between channel foundation soil and the neighboring compound geo-membrane structure surface, Dong Jiangwei [5] gave a finite element analysis of the frost heaving damage of rigid-flexible lining channel with large section.Song Ling[6] created the mathematical model for frost heaving of conveyance channel operated in winter from the perspective of temperature and moisture content binary composite field. Based on the mathematical control equation for soil with solid-liquid compatibility and in mutual heat transfer and with the level-4 conveyance channel Shihezi Hongshanzui power plant as the research object,this paper gives a numerical simulation analysis by means of convective heat transfer in order to provide suggestions on future design of concrete conveyance channel operated in winter.

\section{Temperature-Water Content Binary Field}

1.1 Temperature-water content binary coupling field for conveyance channel not operated

The cross-section of channel in seasonal frozen soil is a compound coupling temperature- moisture field. As shown in Fig. 1, the gas-face surface of the coupled field is a curving concave line but that of the original channel bed is a straight line. When the temperature over the channel drops below $0^{\circ} \mathrm{C}$, 
the temperature-thermal coupling fields for the two channels are different. If the water content of the soil below embankment $A$ is equal or above the critical moisture content of frost heave of the soil, frost heave phenomenon and frost heave effect will finally occur in the neighboring soil. Nevertheless, that frost heaving it is unlike frost heaving of the original channel bed and different from that of rigid-flexible coupling field.

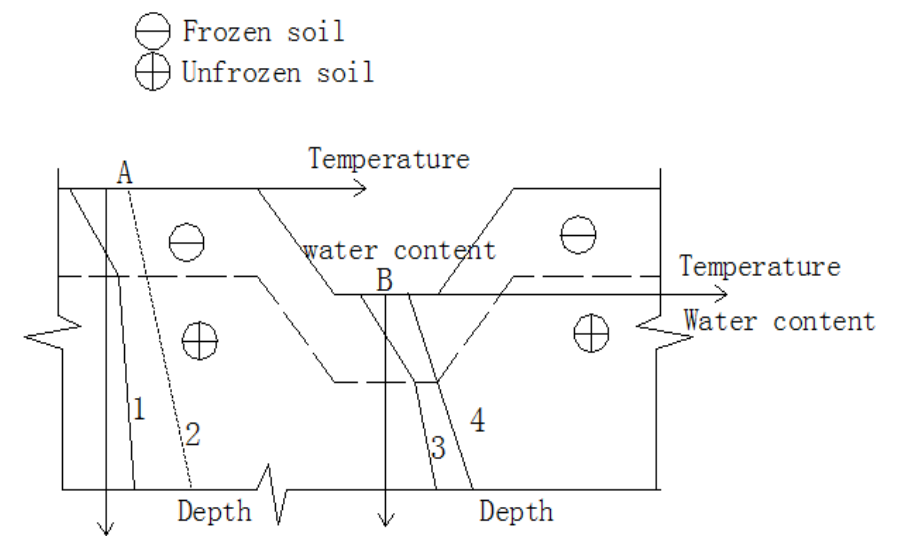

1. Temperature of soil with any depth below channel embankment A; 2 . Water content of soil with any depth below channel embankment A; 3. Temperature of soil with any depth below channel bottom B; 4. Water content of soil with any depth below channel bottom B;

Fig. 1. Diagram on Temperature and Water Content of Special Positions of the Channel

Foundation Soil Cross-section in Temperature- Water Content Binary Coupling Field

1.2 Temperature-water content binary coupling field for lining conveyance channel

For lining conveyance channel in extremely cold area, its cross-section is also a "coupling” field-moisture field and temperature field. Under channel water supply in winter, gradient trends of the water content of the soil below the channel embankment, channel slope and baseplate are as shown in Fig. 2, which reflect some differences. It is seen that soil water content of the soil below channel slope $\mathrm{C}$ is greatly bigger than that of the soil under original state, and the seepage rate is relatively greater, which decreases as infiltration progresses and finally reaches a stable state. This is because the wetting front travels a short distance in early period of seepage when the hydraulic gradient is bigger, and then the hydraulic gradient decreases rapidly and gradually becomes stable[7].

$$
\bigoplus \text { Frozen soil }
$$

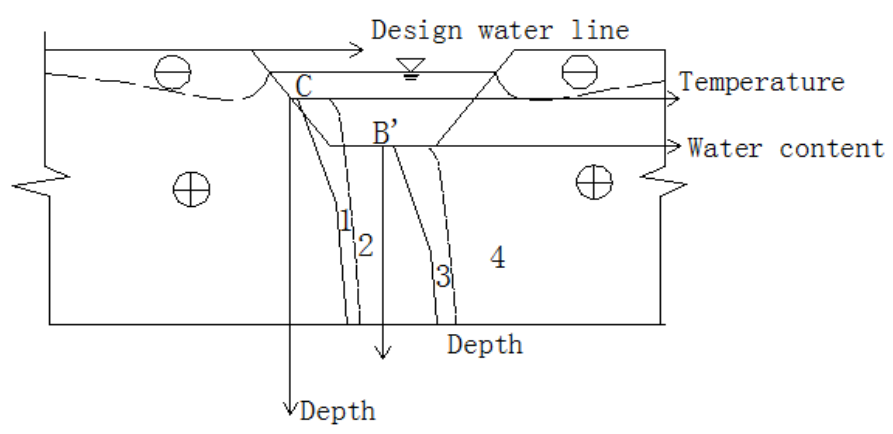

1. Temperature of soil with any depth below channel slope C; 2 . Water content of soil with any depth below channel slope C; 3. Temperature of soil with any depth below channel bottom B'; 4 .

Water content of soil with any depth below channel bottom B';

Fig. 2. Diagram on Temperature and Water Content of Special Positions of the Channel Foundation Soil Cross-section in Temperature- Water Content Binary Coupling Field

\section{Establishment of Mechanical Model}

\subsection{Heat transfer analysis}


During heat transfer, due to slow freezing process of channel foundation soil and long duration, we can regard it as steady-state heat transfer process (irrespective of the great heat released during phase change). Meanwhile, the problem of channel frost heaving is simplified into a plane problem, thus, the contact heat transfer control equation for two-dimensional plane strain problem under a steady state is:

$$
\frac{\partial}{\partial_{\mathrm{x}}}\left(\lambda_{\mathrm{x}} \frac{\partial T}{\partial \mathrm{x}}\right)+\frac{\partial}{\partial_{\mathrm{y}}}\left(\lambda_{\mathrm{x}} \frac{\partial T}{\partial \mathrm{y}}\right)=0 \quad(\mathrm{x}, \mathrm{y}) \in A
$$

Wherein: $\mathrm{T}$ represents temperature; $\lambda_{\mathrm{x}}$ and ${ }^{\lambda_{\mathrm{y}}}$ represent heat conductivity coefficient of the frozen soil along $\mathrm{x}$ and $\mathrm{y}$ direction; A represents the calculated area in frost heave. For frozen soil, its heat conductivity coefficient changes slightly with temperature, but varies greatly with water content of soil body. That is to say, the smaller the water content is, the smaller the heat conductivity coefficient and the greater thermal resistance is[8].

2.2 Frost heave mechanism and material convective heat transfer model

If the fine-grained soil in the soil body is frozen under a small freezing rate, temperature gradient effect is generated and water flowing is accelerated consequently. Water flow rushes into the freezing surface and gathered here, becomes bigger and bigger in volume. The soil body is influenced by composition, density and moisture. In this paper, the complex process of water migration is neglected and frozen soil is regarded as isotropic perfectly elastic material and its elastic modulus varies with temperature[9]. For convective heat transfer produced by the fluid passing through the wall.

\section{Fluid particle}

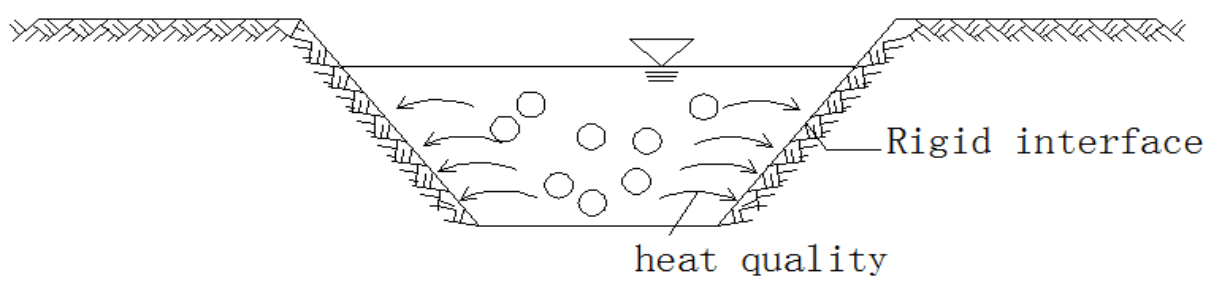

Fig.3 Diagram of Fluid Convective Heat Transfer in Winter Conveyance Channel

In view of physical conditions, it is assumed that the fluid in uniform velocity and convection only occurs along the direction parallel to wall surface, according to the classical theory concerning convection heat transfer of viscous fluid, heat exchange between the flow and solid wall is only realized by heat transfer under the premise of no slip of the fluid and wall. On this basis, the following formula of convective heat-transfer coefficient is obtained [10]:

$$
\mathrm{h}_{\mathrm{x}}=\frac{-\left.\lambda \frac{\partial \mathrm{t}}{\partial \mathrm{y}}\right|_{\mathrm{y}=0}}{\left(\mathrm{t}_{\mathrm{w}}-\mathrm{t}_{\infty}\right)}
$$

Wherein: $\lambda$ represents heat conductivity coefficient of the fluid, $t_{w}$ and $t_{\infty}$ represent the temperature of the incoming flow and wall surface respectively. $\left.\frac{\partial \mathrm{t}}{\partial \mathrm{y}}\right|_{\mathrm{y}=0}$ is the rate of change in temperature of the fluid along normal direction of the adherence wall.

\section{Prototype Summary}

The prototypes of the simulation calculation in this paper are the level-4 diversion canal T-shape channel section of Hongshanzui power plant in Xinjiang, which is $4.153 \mathrm{~km}$ in length, $3.0 \mathrm{~m}$ in base width and 4.5m in depth and the C20 concrete lining seepage-proof channel with 3.5m depth of water, $0.2 \mathrm{~m}$ in length of side and thickness of base plate, with longitudinal slope grade of 1/1 400 and side 
slope grade of $1 / 1.75$. The maximum thickness of the frozen soil is $1.3 \mathrm{~m}$ and friction coefficient between channel foundation soil and concrete plate is 0.35 . Through water intaking for many times in various positions with small kettle to measure the average temperature, it is found in this paper[11] that the water temperature along the flow direction ranges from 0.5 to $2.8^{\circ} \mathrm{C}$ during operation of the channel in winter. Therefore, the fluid in the channel would not be frozen under normal conditions.

3.1 Parameter Calculation

For heat conduction under a steady state, the temperature distribution of different materials is influenced by heat conductivity coefficient $\lambda$. Concrete heat conductivity coefficient $\lambda_{\mathrm{c}}=1.65 \mathrm{~W} /\left(\mathrm{m} \cdot{ }^{\circ} \mathrm{C}\right)$ [12]. According to heat conduction equation, the heat conductivity coefficient of frozen soil $\lambda_{\mathrm{f}}=1.9870 \mathrm{~W} /\left(\mathrm{m} \cdot{ }^{\circ} \mathrm{C}\right)$. Geometric model is established with due consideration given to boundary conditions and is the simplified version of that for the original channel. Assuming water temperature is under normal temperature of $2^{\circ} \mathrm{C}$, the channel model is infinite in length, thus, the geometric model is transformed into a plane element. There is no displacement in the lower boundary of the model, $\mathrm{X}$ direction is the free boundary and the two directions of the upper boundary are both free boundaries. Stress boundary conditions: shear stress of the left and right boundaries is 0 . Table 1 gives the elastic modulus of frozen soil under certain water content at different ice volume[12]. The value of linear expansion coefficient is determined by $\eta / T_{\min }, \eta$ is the frost-heaving ratio, and $T_{\min }$ is the minimum value of the monthly average surface temperature of the corresponding position.

Selection[13] of corresponding mechanical parameters is as shown in Table 2.

Table 1. Equivalent Modulus of Frozen Soil

\begin{tabular}{|c|c|c|c|c|c|}
\hline $\begin{array}{l}\text { Ice Volume } \\
\text { Content / \% }\end{array}$ & $\begin{array}{l}\text { Ice Temperature } \\
/^{\circ} \mathrm{C}\end{array}$ & $\begin{array}{l}\text { Ice } \mathrm{E} \\
/ M l\end{array}$ & stic Modulus & $\begin{array}{l}\text { Soil Elastic } \\
\text { Modulus / } \mathrm{MPa}\end{array}$ & $\begin{array}{l}\text { Elastic Modulus of } \\
\text { Frozen Soil / } \mathrm{MPa}\end{array}$ \\
\hline & -2.0 & 4910 & & & 291.6 \\
\hline \multirow[t]{2}{*}{0.05} & -5.4 & 6342 & & \multirow[t]{2}{*}{46.0} & 363.3 \\
\hline & -8.0 & 6820 & & & 387.2 \\
\hline \multirow[t]{4}{*}{0.1} & -2.0 & 4910 & & \multirow[b]{2}{*}{46.0} & 535.0 \\
\hline & -5.4 & 6342 & & & 678.2 \\
\hline & -8.0 & 6820 & & & 726.1 \\
\hline & -2.0 & 4910 & & & 1021.3 \\
\hline \multirow[t]{2}{*}{0.2} & -5.4 & 6342 & & 46.0 & \multirow{2}{*}{$\begin{array}{l}1307.7 \\
1403.3\end{array}$} \\
\hline & -8.0 & 6820 & & & \\
\hline \multicolumn{6}{|c|}{ Table 2 Material Mechanics Parameters } \\
\hline Medium & \multicolumn{2}{|c|}{$\begin{array}{l}\text { Elasticity Modulus } \\
\qquad E / p a\end{array}$} & $\begin{array}{c}\text { Poisson's ratio } \\
v\end{array}$ & $\begin{array}{l}\text { Heat Conductivity } \\
\text { Coefficient } \lambda / \\
W \cdot \mathrm{m}^{-1} \cdot{ }^{\circ} C^{-1}\end{array}$ & $\begin{array}{c}\text { Coefficient of } \\
\text { Linear Expansion } \\
\alpha /\left(1{ }^{\circ} C^{-1}\right)\end{array}$ \\
\hline Concrete & \multicolumn{2}{|c|}{$24 \times 10^{10}$} & 0.167 & 1.58 & $1.1 \times 10^{5}$ \\
\hline Joint Filler & \multicolumn{2}{|c|}{$2 \times 10^{5}$} & 0.45 & 1.21 & 0 \\
\hline
\end{tabular}

\subsection{Calculation Results}

\subsubsection{Temperature Field}

From Fig. 4, we can clearly see the changes of the simulated temperature field of the conveyance channel. Frozen front is in different depth and frost depth of channel embankment soil reaches $148 \mathrm{~cm}$ for it is directly exposed to atmospheric minus temperature. While, the channel slope (below the water line) and the soil below the bottom plate in direct contact with the fluid in the channel are not frozen because of increase in water content caused by heat transfer and seepage of the lining. 


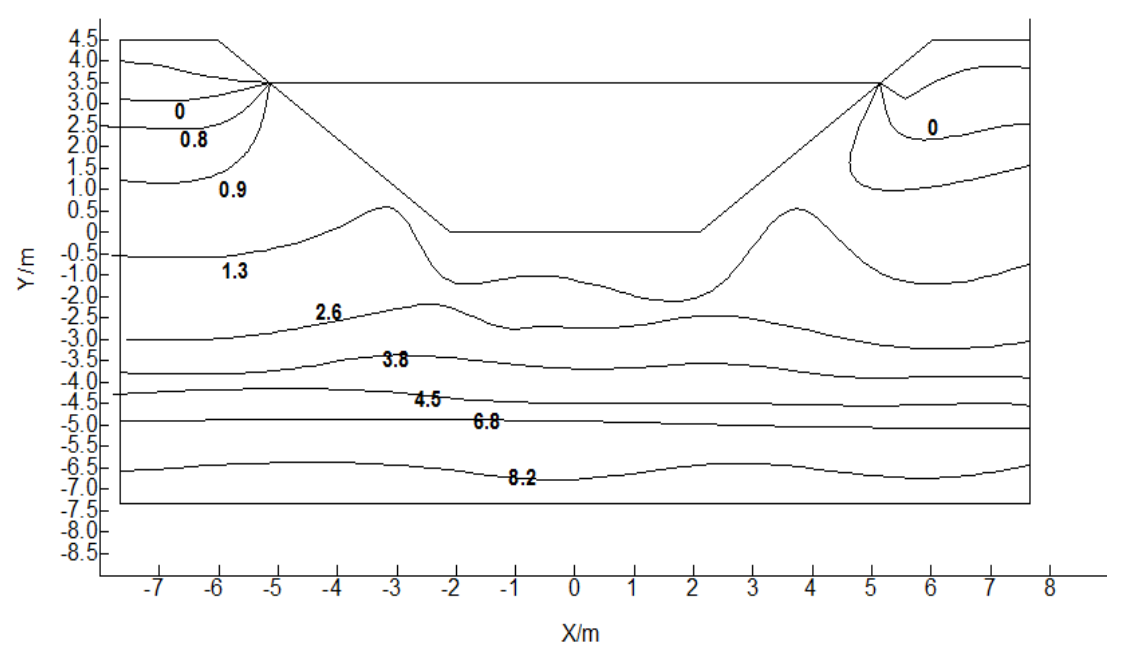

Fig. 4 Distribution Map of Temperature Field

\subsubsection{Calculation results of displacement field}

Displacement distribution map obtained through numerical simulation results is as shown in Fig. 5. It is indicated that there is obvious bulging deflection in the channel embankment and channel slope above the water line.

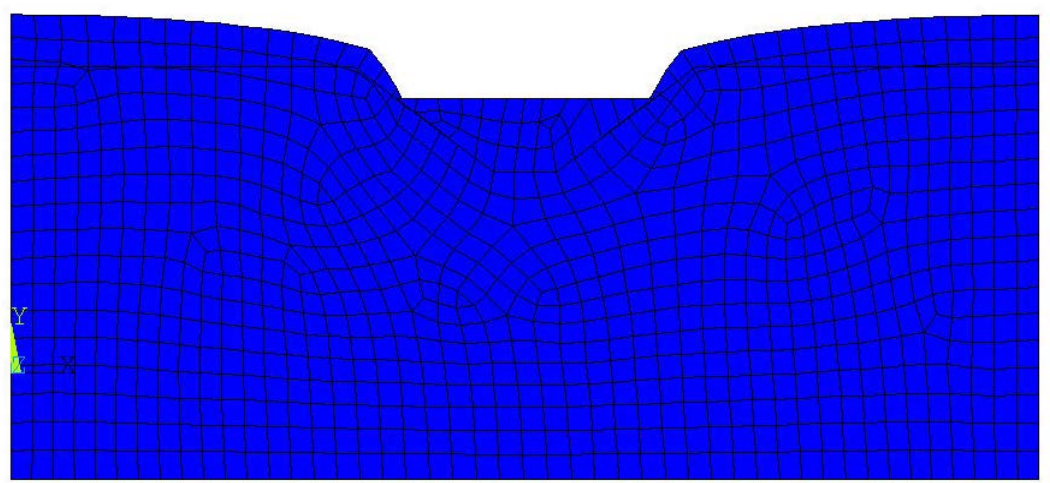

Fig. 5 Frost Heave Displacement Distribution Map of Conveyance Channel 3.2.3 Calculation results of stress field

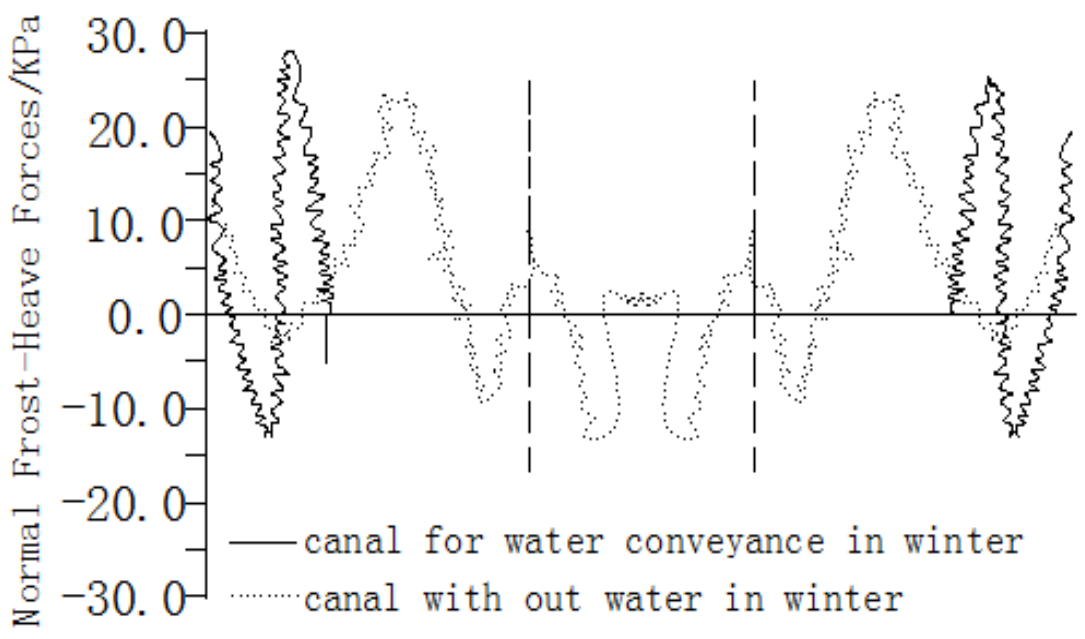

Fig. 6. Normal Frost-Heave Force Distribution Map 


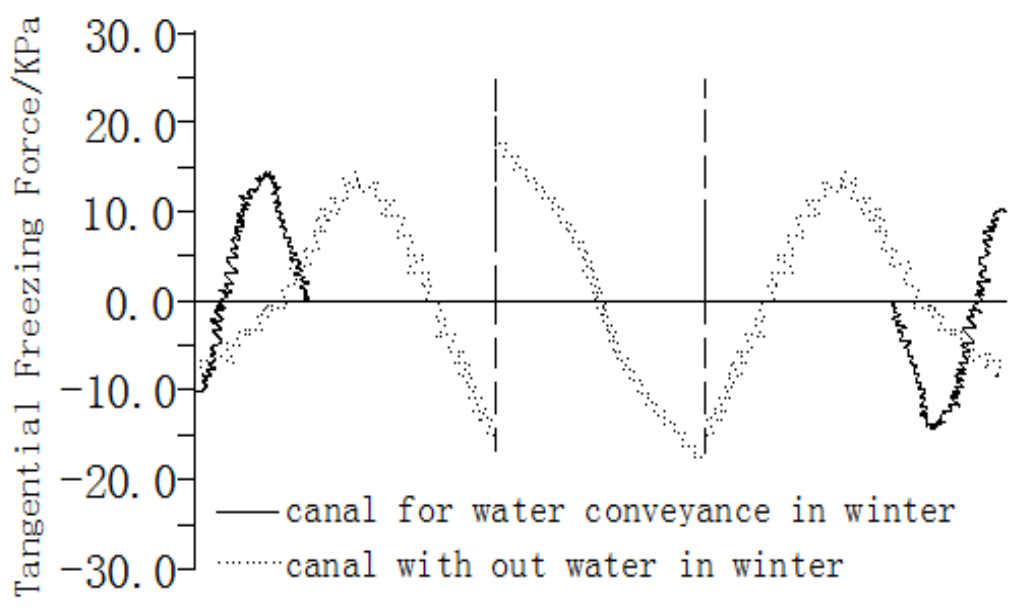

Fig. 7. Tangential Freezing Force Distribution Map

The normal frost-heave force above the water line in the two models is in similar frost heaving,but the distribution would become more uneven due to big deformation of channel model in winter caused by frost heaving. It is shown by Fig. 6 that: there is great change in normal frost-heave force of the two models on the water line: in the minus temperature section, the two sides of the slope with 1/3 of the distance from the water line of concrete channel operated in winter are under tension, and the two sides with $1 / 3$ of the distance from the channel top are under pressure. Due to stress features of great compression strength and low tensile strength of the the concrete lining layer, the channel slope with $1 / 3 \sim 1 / 2$ of the distance from the water line is prone frost heave damage, which basically conforms to the actual project conditions.

The frost-heave force of the surface under concrete rigid lining plate is distributed as shown in Fig. 7. The frost-heave force along the pulling-out direction of the channel slope is the tangential force. Divided by the position with $1 / 3$ of the distance from the bottom of channel not operated in winter, the frost-heave force of the north-faced slope and south-faced slope is along the pulling-out direction of the concrete lining plate length from the diving point, therefore, this position is prone to damage, which is proved by engineering practice. However, the tangential frost-heave force of the channel operated in winter is divided by the position with $1 / 3$ of the distance from the top of the water line and it reached peak value of $15 \mathrm{KPa}$ at this position. This better reveals damage of high slope in the conveyance channel after a cold winter.

\section{Conclusions}

1) With the use of ANSYS finite element software for analysis of conveyance channel operated in winter, this paper concludes the results that can basically reflect the stress distribution pattern of the frost-heave deformation channel and frost-heave rules and meet the accuracy requirement. Thus, it can provide reference and suggestions for design and construction of the concrete lining channel operated winter.

2) Through finite element simulation analysis of the conveyance channel operated in winter, it is indicated that, in the course of time, the frost depth of the channel increases under water convective heat transfer and temperature gradient, which is in line with actual project conditions.

3) Numerical calculation results show that, the normal frost-heave force of the soil near the position with $1 / 3$ distance from the water line along the slope length reaches $28.5 \mathrm{KPa}$. It is easy to see in the stress filed that the frost-heave force is in peak value. Hence, after a cold winter, it is often found that the frost heaving damage in conveyance channel operated winter is greater than that in channel not operated in winter. This is also proved by practice.

\section{Acknowledgments}

This work was supported by National Natural Science Foundation of China(51669031). 


\section{References}

[1] Harlan R L. Analysis of Coupled Heat-Fluid Transport in Partially Frozen Soil[J].Water Research,1973,9(5):1314-1323.

[2] Shen Mu, Branko Ladanyi.1990 Modeling of Coupled Heat, Moisture And Stress Field in Freezing Soil, Cold Region Science and Technology, 14:237-240.

[3] An Weidong, Chen Xiaobai, Wu Ziwang, Numerical Simulation of Heat and Mass Transfer in Frozen Channel [J], Journal of Glaciology and Geocryology, 1987, 1(9): 35-46.

[4] Konrad J M, Morgenstern N R. Prediction of frost heave in thelaboratory during transient freezing[J]. Canadian GeotechnicalJournal, 1982, 19(3): 250-259.

[5] Dong Jiangwei, Tang Hua and Jiang Haibo, Finite Element Analysis of Frost Heaving of Rigid-Flexible Lining Channel with Large Section [J], Journal of Yellow River, 2016, (11):149-152.

[6] Song Ling, Ouyang Hui and Yu Shuchao, Frost-heave Force and Freezing-resistant Force Calculation of Concrete Seepage-proof Conveyance Channel in Winter Delivery[J], Journal of Agricultural Engineering, 2015, 18:114-120.

[7] Kang Shaozhong, Su Xiaoling, Shen Qinglin, Shi Zepei and Yang Xiuying, Strategic Thinking on Water Resources Utilization and Water-saving Agricultural Development Pattern in Shiyang River Basin [J], Journal of Water Resources and Water Engineering, 2004, (04):1-8.

[8] Xu Xuezu, Wang Jiacheng and Zhang Lixin, Physics of Frozen Soil [M], Beijing: Sincere Press, 2010.

[9] Chen Xiaobai, Liu Jiankun and Liu Hongxu etal. Soil Freezing Effect and Foundation [M], Beijing: Sincere Press, 2006.

[10] Chen Hui, Chen Shannian and Xu Yiqian, Theoretical Solution to Ideal Fluid Convective Heat Transfer[J], Journal of Thermal Science and Technology, 2004, (03):200-204.

[11] Huang Jiulin, Zong Quanli, Liu Zhenji etal. Ice Melting Prototype Test and Analysis of Pump for Diversion Channel in Alpine Region [J], Journal of Shihezi University (Natural Science Edition), 2014, 03:392-396.

[12] Liu Xiong, Ning Jianguo, and Ma Wei, Numerical Analysis of Temperature Field and Stress Field in Water Channel in Frozen-earth Region, Journal of Glaciology and Geocryology, 2005, 06:932-938.

[13] Zhang Jie, Xu Wei and Zhong Jianchi, Whole-process Numerical Simulation of Temperature Field in Anchorage of Ultra-deep Foundation Pit Support in Runyang Yangtze River Bridge by Freezing Method Construction [J], Journal of Construction, 2004, 01:15-17. 